\title{
A complex acid-base disorder in an alcoholic
}

\author{
Elvira Umyarova MD, Natasha Suvorava MD
}

\section{CASE}

A 49-year-old man with a history of PTSD, panic attacks, and recent alcohol binge drinking with rapid cessation presented with anxiety, shortness of breath, and multiple vomiting episodes. Laboratory tests included $\mathrm{Na} 140 \mathrm{mmol} / \mathrm{L}, \mathrm{K} 4.8 \mathrm{mmol} / \mathrm{L}, \mathrm{Cl} 81$ $\mathrm{mmol} / \mathrm{L}, \mathrm{CO}_{2} 9 \mathrm{mmol} / \mathrm{L}$, BUN $26 \mathrm{mg} / \mathrm{dl}, \mathrm{Cr} 1.8 \mathrm{mg} /$ $\mathrm{dl}$, glucose $250 \mathrm{mg} / \mathrm{dl}$, albumin $5.7 \mathrm{gm} / \mathrm{dl}$, and amylase 243 int unit/L ( $\mathrm{nl}$ 13-60 int units/L). The serum anion gap was 50 , acetone large, osmolal gap 13 , serum ethanol negative, salicylate level negative, and $\mathrm{HbA} 1 \mathrm{c}$ normal. Arterial blood gases included $\mathrm{pH} 7.46$, $\mathrm{pCO}_{2} 14.4 \mathrm{mmHg}, \mathrm{HCO}_{3} 10.1 \mathrm{mEq} / \mathrm{L}$, base excess (-) $10.2 \mathrm{mEq} / \mathrm{L}$, lactate $3.0 \mathrm{mmol} / \mathrm{L}$, and $\mathrm{pO}_{2} 104 \mathrm{mmHg}$ on $\mathrm{FiO}_{2} 21 \%$. The urine contained ketones but no glucose. What is the diagnosis?

\section{Discussion}

This patient has a complex acid-base disorder with mild alkalemia, hypocapnea, and a wide anion gap. The wide anion gap and base deficit indicate that he has metabolic acidosis. The clinical history suggests that he also has metabolic alkalosis secondary to recurrent vomiting and primary hyperventilation possibly related to anxiety. The $\mathrm{pCO}_{2}$ is clearly too low given the $\mathrm{pH}$ and too low given his current bicarbonate level if it represented respiratory compensation for acidemia. This presentation is consistent with alcoholic ketoacidosis, and this disorder represents a primary emphasis in our discussion.

Metabolic acidosis is a clinical condition characterized by low a $\mathrm{pH}$, a low $\mathrm{HCO}_{3}$, and compensatory hyperventilation resulting in a low $\mathrm{pCO}_{2}$. It can be induced by the addition of a strong acid partially buffered by $\mathrm{HCO}_{3}$ or by the loss of $\mathrm{HCO}_{3}$ from body

Corresponding author: Natasha Suvorava, MD Contact Information: natallia.suvorava@ttuhsc.edu DOI: 10.12746/swrccc2013.0206.068 fluid. Calculation of serum anion gap is very helpful in the differential diagnosis and is equal to the difference between measured anions and cations. Based on that calculation metabolic acidosis can be divided into high anion gap metabolic acidosis (HAGMA) and non-anion gap metabolic acidosis. HAGMA encompasses disorders of organic acidosis resulting from increased acid production and can be further classified into:

1) Ketoacidosis due to diabetes mellitus, alcohol ingestion, or starvation

2) Lactic acidosis (type A, type $B$, and D lactic acidosis)

3) HAGMA due to ingestion of methanol, ethylene glycol, propylene glycol, salicylates

4) HAGMA due to renal failure

Alcoholic ketoacidosis should be strongly suspected in patients with a history of alcohol abuse and rapid cessation of binge drinking who present with unexplained HAGMA and superimposed metabolic and respiratory alkalosis. This condition usually presents in chronic alcoholics after binge drinking with little solid food intake followed by severe vomiting due to acute gastritis or pancreatitis which results in severe volume contraction. This sequence of events leads to an increase in sympathetic drive causing a decrease in insulin secretion and an increase in counter regulatory stress hormones, including glucagon, catecholamines, and growth hormone. It causes marked insulin resistance and increased release of fatty acids into circulation with their subsequent metabolism to ketoacids by the liver. Lipolysis is also favored by depletion of hepatic glycogen stores secondary to starvation.

Alcohol metabolism also contributes to ketoacidosis. Alcohol dehydrogenase and aldehyde dehydrogenase metabolize alcohol to acetaldehyde and subsequently to acetic acid in mitochondria. This leads to reduction of the ratio of NAD to NADH which 
causes inhibition of hepatic gluconeogenesis. Due to high NADH: NAD ratio generated acetyl-CoA is not processed by citric acid cycle and is diverted to ketogenesis with the production of B-hydroxybutyrate and acetoacetic acids. The accumulation of ketones results in HAGMA. As a result of persistent vomiting there is intravascular volume depletion with consequent decrease of renal excretion of ketoacids, which contributes to the worsening of HAGMA. Furthermore, oxidation of fatty acids generates an excess amount of glycerol which in combination with ethanol leads to an increased osmolal gap. Understanding of these pathophysiological processes helps to guide the treatment strategies, which are directed toward rehydration, removal of sympathetic drive, and stimulation of insulin secretion.

\section{Table Summary of recent alcoholic ketoacidosis case reports}

\begin{tabular}{|c|c|c|c|c|c|c|}
\hline $\begin{array}{l}\text { Alcohol in- } \\
\text { gestion, Ref \# }\end{array}$ & Age, Gender & $\mathrm{pH}$ & HCO3/AG & Glucose & Treatment & Outcome \\
\hline $\begin{array}{l}\text { Ceased abruptly } \\
\text { Ref \#3 }\end{array}$ & $60, \mathrm{~F}$ & 7.13 & $\mathrm{NA} / 41$ & 20 & $50 \%$ dextrose, vitamins B \& C & survival \\
\hline $\begin{array}{l}\text { Ceased abruptly } \\
\text { Ref \#5 }\end{array}$ & $54, \mathrm{M}$ & 7.04 & $4.3 / 38$ & 108 & IV thiamine, bicarbonate & survival \\
\hline $\begin{array}{l}\text { Ceased abruptly } \\
\text { Ref \#5 }\end{array}$ & $44, \mathrm{M}$ & 6.87 & $4.3 / 46$ & 97 & $\begin{array}{l}\text { IV thiamine, hemodialysis, IV ethanol } \\
\text { (for possible methanol ingestion) }\end{array}$ & death \\
\hline $\begin{array}{l}\text { Current } \\
\text { Ref \#2 }\end{array}$ & $51, F$ & 6.7 & $11 / 38.3$ & 132 & ACLS, bicarbonate & survival \\
\hline $\begin{array}{l}\text { Current } \\
\text { Ref \#2 }\end{array}$ & $53, M$ & 6.4 & $3.8 / 54.9$ & 241 & ACLS, bicarbonate, hemofiltration & survival \\
\hline $\begin{array}{l}\text { Current } \\
\text { Ref \#2 }\end{array}$ & $63, M$ & 7.35 & $11.5 / 34.9$ & 546 & Normal saline, diazepam & death \\
\hline $\begin{array}{l}\text { Current } \\
\text { Ref \#2 }\end{array}$ & $44, \mathrm{M}$ & 6.7 & $1.6 / 54.6$ & 117 & Ringer's lactate, bicarbonate & survival \\
\hline $\begin{array}{l}\text { Ceased } \\
\text { Ref \#4 }\end{array}$ & $62, \mathrm{M}$ & 7.17 & $5.8 / 35.2$ & 428 & $\begin{array}{l}\text { Normal saline, insulin, gebexate } \\
\text { mesilate, antibiotics }\end{array}$ & survival \\
\hline $\begin{array}{l}\text { Current } \\
\text { Ref \#4 }\end{array}$ & $53, M$ & 6.93 & $2.6 / 48.4$ & 286 & $\begin{array}{l}\text { Thiamine, gebexate mesilate, antibi- } \\
\text { otics, hemodialysis }\end{array}$ & survival \\
\hline
\end{tabular}


Gebexate mesilate- synthetic protease inhibitor

The Table summarizes key information collected from recent case reports with alcoholic ketoacidosis. The typical patient is a middle aged man with a history of chronic alcohol intake and current or recent binge drinking who presents with multiple episodes of nausea and vomiting, confusion, severe HAGMA, and either hypoglycemia or hyperglycemia. Most episodes of uncomplicated alcoholic ketoacidosis have a good prognosis, but multiple complications can occur. Patients may develop acute renal failure, probably secondary to rhabdomyolysis, acute liver failure, acute pancreatitis, and rarely acute heart failure, probably secondary to beri beri heart disease. Sudden cardiac arrest can occur in these patients.

CASE REVIEW: Our patient had most of the features of a typical alcoholic ketoacidosis patient; he presented with a severe anxiety episode and shortness of breath after rapid cessation of alcohol consumption and was found to have a HAGMA with significantly elevated anion and osmolal gaps and large ketones in blood and urine. The slightly elevated serum $\mathrm{pH}$ is explained by respiratory compensation $\left(\mathrm{pCO}_{2}=14\right)$ and by metabolic alkalosis due to multiple episodes of vomiting. This patient did not have a history of diabetes mellitus and, despite initially elevated serum blood glucose levels, did not have glucosuria or an abnormal $\mathrm{HbA} 1 \mathrm{c}$. The patient rapidly responded to administration of normal saline, dextrose, and thiamine.

\section{KEY POINTS}

1. Alcoholic ketoacidosis is an underdiagnosed medical emergency. This condition is usually identified in chronic alcohol abusers following an abrupt cessation or reduction of alcohol intake.

2. Patients present with HAGMA, elevated osmolal gap, and elevated acetone and b-hydroxybutyrate levels. Clinical findings are very similar to diabetic ketoacidosis but there is usually no history of diabetes and glucose levels are variable.

3. The diagnosis of alcoholic ketoacidosis may be obscured by absence of acidemia secondary to com- pensation mechanisms of respiratory alkalosis and metabolic alkalosis due to vomiting, undetectable ethanol levels, and frequent false negative results of urine ketones.

4. Presentation of alcoholic ketoacidosis can mimic other conditions with HAGMA, particularly the ingestion of unusual alcohols, such as ethylene glycol and methanol. It is important to distinguish between these conditions as the former promptly responds to the administration of fluids whereas the recommended therapy for the other toxic ingestions can significantly worsen the outcome in patients with alcoholic ketoacidosis.

5. The diagnosis carries a good prognosis; patients have a rapid response to treatment with normal saline, dextrose, and thiamine replacement. Generally, the administration of insulin or bicarbonate is not needed.

KeY wORDS: high anion gap metabolic acidosis, alcoholic ketoacidosis, chronic alcohol abuse.

Author Affiliation: Elvira Umyarova and Natasha Suvorava are residents in Internal Medicine at TTUHSC.

Received: $1 / 4 / 2014$

Accepted: $4 / 7 / 2014$

Reviewers: Melvin Laski MD

Published electronically: 1/15/2014

Conflict of Interest Disclosures: None

\section{REFERENCES}

1. McGuire L, Cruickshank A, Munro P. Alcoholic ketoacidosis. Emerg Med J 2006; 23: 417-420.

2. Yanagawa Y, Sakamoto T, Okada Y. Six cases of sudden cardiac arrest in alcoholic ketoacidosis. Int Med 2007; 113117.

3. Ngatchu T, Sangwaiya A, Dabiri A, Dhar A, McNeil A, McNeil I, Arnold J. Alcoholic ketoacidosis with multiple complications: a case report. Emerg Med J 2007; 24:776777. 
4. Tanaka M, Myyazaki Y, Ishikawa S, Matsuyama K. Alcoholic ketoacidosis associated with multiple complications: report of 3 cases. Internal Medicine 2004; 43 (10): 955-959. 5. Chiu R, Tai H, Lam C. Alcoholic ketoacidosis in two Chinese patients. Chinese Medical J 2000; 113 (11):1051-1053. 6. Sabatine M. Pocket Medicine: The Massachusetts General Hospital Handbook of Internal Medicine (Pocket Notebook Series), 4th, edition, 2011 